\title{
Sequence differences in the internal transcribed spacer 1 and 5.8S ribosomal RNA among three Moniezia species isolated from ruminants in Japan
}

\author{
Maiko OHTORI ${ }^{1}$, Mikiko AOKI ${ }^{1)}$ and Tadashi ITAGAKI $^{1) *}$ \\ ${ }^{1)}$ Laboratory of Veterinary Parasitology, Faculty of Agriculture, Iwate University, Ueda 3-18-8, Morioka 020-8550, Japan
}

(Received 16 June 2014/Accepted 16 September 2014/Published online in J-STAGE 3 October 2014)

\begin{abstract}
This study was designed to clarify the differences in the internal transcribed spacer (ITS) 1 and 5.8S nucleotide sequences of Moniezia expansa, M. benedeni and M. monardi isolated from ruminants in Japan and to determine their phylogenetic relationships. A $98 \%$ similarity in the $5.8 \mathrm{~S}$ sequences was observed among the 3 Moniezia species, whereas many nucleotide indels and substitutions were observed in the ITS1 sequences among the three Moniezia species. These results suggest that the ITS1 region could serve as a potential marker for discriminating the 3 Moniezia species. In the phylogenetic tree based on the ITS1 sequences, M. monardi and M. benedeni showed genetically closer relationship to each other than to M. expansa.
\end{abstract}

KEY WORDS: 5.8S rRNA, ITS1, Moniezia benedeni, Moniezia expansa, Moniezia monardi, phylogeny

doi: 10.1292/jvms.14-0309; J. Vet. Med. Sci. 77(1): 105-107, 2015

Moniezia cestodes of the family Anoplocephalidae are intestinal parasites of animals belonging to the orders Perissodactyla, Artiodactyla and Primates. At least 12 Moniezia species have been identified in domestic and wild ruminants [8], and 3 of these, namely, M. expansa, M. benedeni and $M$. monardi have been detected in sheep, cattle and Japanese serows (Capricornis crispus), respectively, in Japan [2, 5, 6]. The 3 cestode species have been differentiated based on morphological differences, such as their interproglottidal glands and eggs; however, it is common to find individuals that lack the interproglottidal glands, and the proglottids excreted into the feces sometimes have no interproglottidal glands. Moreover, the excreted eggs are sometimes deformed altering their diagnostic outer shell characteristics, preventing morphological differentiation up to the species level $[10,12]$.

Recently, molecular identification of parasitic helminthes has been developed using nucleotide sequences of the nuclear ribosomal RNA (rRNA) genes [1, 7, 13]. The internal transcribed spacer (ITS) regions within the rRNA gene have been used as molecular markers of species identification, because of the unequivocal differences in the sequence of closely related species and minimal intraspecific sequence variations. The 5.8S rRNA gene shows conserved sequences; therefore, its sequence has been used for phylogenetic analysis among distantly related organisms belonging to higher taxa and for designing their common PCR primers. The present study was designed to identify the differences in the ITS1 and 5.8S nucleotide sequences and thus establish the phylogenetic relationships among $M$. expansa, M. benedeni

*Correspondence to: Itagaki, T., Laboratory of Veterinary Parasitology, Faculty of Agriculture, Iwate University, Ueda 3-18-8, Morioka 020-8550, Japan. e-mail: itagaki@iwate-u.ac.jp

(C)2015 The Japanese Society of Veterinary Science

This is an open-access article distributed under the terms of the Creative Commons Attribution Non-Commercial No Derivatives (by-nc-nd) License $<$ http://creativecommons.org/licenses/by-nc-nd/3.0/>. and $M$. monardi.

We used 13 Moniezia cestodes (7 M. monardi, $3 \mathrm{M}$. benedeni and $3 \mathrm{M}$. expansa) isolated from the intestines of 13 distinct animals (7 Japanese serows, 3 cattle and 3 sheep, respectively) in Iwate and Akita Prefectures, Japan, during 1993 and 2006. The proglottides of these cestodes that were fixed with $70 \%$ ethanol were stained with HematoxylinCarmine solution for morphological observation, and the species were precisely identified based on Schmidt [8], Spassky [10] and Machida et al. [5], especially depending on the shape of their interproglottid gland.

Total DNA was extracted from the proglottides of individual cestodes by using E.Z.N.A Mollusc DNA kits (Omega Bio-tek, Doraville, GA, U.S.A.) according to the manufacturer's instruction. DNA fragments (approximately 1,700 $\mathrm{bp)}$ were amplified by using the polymerase chain reaction (PCR) using ITS1-F and ITS2-R primers [3]. PCR was performed in a $25-\mu l$ reaction volume containing $2 \mu l$ of DNA template, $0.2 \mathrm{mM}$ of each $\mathrm{dNTP}, 0.1 \mu \mathrm{M}$ of each primer, 1.25 U of GoTaq DNA polymerase (Promega, Madison, WI, U.S.A.) and the manufacturer-supplied reaction buffer. Reaction cycles consisted of an initial denaturation step at $94^{\circ} \mathrm{C}$ for $90 \mathrm{sec}$, followed by 30 cycles at $94^{\circ} \mathrm{C}$ for $90 \mathrm{sec}, 53^{\circ} \mathrm{C}$ for $90 \mathrm{sec}$ and $72^{\circ} \mathrm{C}$ for $120 \mathrm{sec}$, with a final extension at $72^{\circ} \mathrm{C}$ for 10 min using the GeneAmp PCR Systems 2700 (Applied Biosystems, Tokyo, Japan). PCR amplicons were precipitated with ethanol / sodium acetate, dissolved in MilliQ water and directly sequenced in both directions by using two forward primers, MO6 (5'-GATGAAGAGTGCAGCCAAC-3') and MO12 (5'-GCAAGGCATAAGACGTTTGG-3') and a reverse primer, MO11 (5'-TGATCCACCGCACACAGT-3'), as well as the same primer set used for PCR and a BigDye Terminator v3.1 Cycle Sequencing Kit (Applied Biosystems, Foster City, CA, U.S.A.). The sequencing reactions were run on a 3500 Genetic Analyzer (Applied Biosystems). The ITS1 and 5.8S sequences were aligned using MAFFT software ver. 7 [4]. A neighbor-joining (NJ) phylogram was 


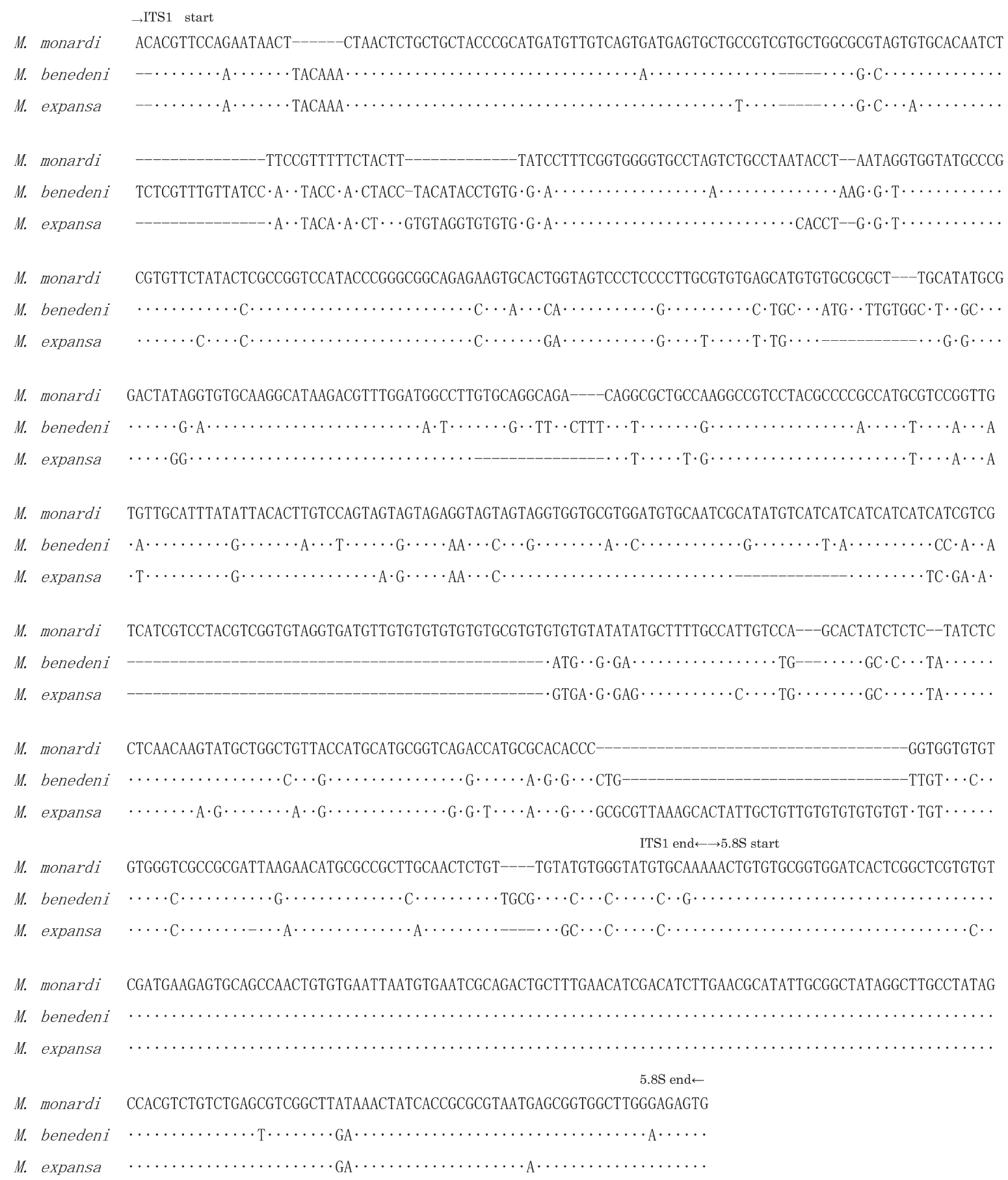

Fig. 1. Sequence alignments of the internal transcribed spacer (ITS) 1 region and 5.8S rRNA gene of 3 Moniezia species. Dots (.) show the identical nucleotide to M. monardi. "-“" shows deletion of nucleotide.

constructed to select complete deletion for gaps/missing data treatment using MEGA5 [11]. For phylogenetic tree construction, the sequence of Dipylidium caninum (accession no. AM491338) was used as the outgroup. Bootstrap analyses were performed using 1,000 replicates.

Single amplicons of approximately $1,700 \mathrm{bp}$ were pro- duced in PCR using 13 DNAs of the three Moniezia species. The amplicons of $7 \mathrm{M}$. monardi and $3 \mathrm{M}$. benedeni could be sequenced from the 5'- end of ITS1 region to the 3 '-end of $5.8 \mathrm{~S}$ using the three forward primers; however, they could not be analyzed using the two reverse primers. No difference in the ITS1-5.8S sequences obtained from $7 \mathrm{M}$. monard $i$ was 


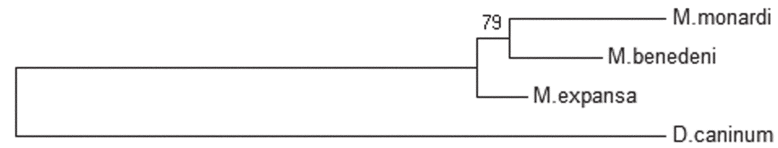

0.05

Fig. 2. A neighbor-joining phylogenetic tree based on the internal transcribed spacer (ITS) 1 sequences of Moniezia expansa, $M$. benedeni and M. monardi.

observed. Similarly, no diversity was observed among the sequences of $3 \mathrm{M}$. benedeni. The amplicons of $3 \mathrm{M}$. expansa could be sequenced through ITS1-5.8S-ITS2 using the five primers, and no difference in these sequences was detected. The ITS1-5.8S sequences determined for the three Moniezia species are shown in Fig. 1. There were many nucleotide indels and substitutions in the ITS1 sequences, and their length were 680,675 and 651 bp for M. monardi, M. benedeni and $M$. expansa, respectively. These results suggest that the ITS1 sequence could serve as a potential marker for differentiating the 3 Moniezia species. However, intraspecific diversity of the ITS1 sequences should be confirmed by sequencing clones of the ITS1 region in a future study, because the occurrence of intragenomic variation has been known in the ITS region. Further diversity analysis is also needed using additional samples of the 3 Moniezia species isolated from distinct geographical areas, because in this study, the number of cestodes $(\mathrm{N}=13)$ and locality from which they were isolated (Iwate and Akita Prefectures) were limited. The 5.8S sequences were $200 \mathrm{bp}$ long in the three species and had no indels. The sequences obtained between the three species showed 98\% similarity. These sequences were deposited in the DNA data bank of Japan (DDBJ) with accession numbers AB367791-AB367793.

In the phylogenetic tree based on the ITS1 sequences, $M$. monardi and $M$. benedeni showed a genetically closer relationship to each other than to $M$. expansa (Fig. 2). A similar topography was also observed in the NJ tree based on the mixed sequences of ITS1 and 5.8S (data not shown). In classical taxonomy of the genus Moniezia, Skrjabin and Schulz [9] divided this genus into 3 subgenera as follows: Moniezia, Blanchariezia and Baeriezia on the basis of the presence and morphological characteristics of the interproglottidal glands. Spassky [10] categorized M. expansa and M. monardi into the same subgenus (Moniezia), in which the interproglottidal glands were grouped around depressions that opened to the surface of the segment (so-called rosettetype) and thus differentiated them from the other subgenus (Blanchariezia), which included M. benedeni with lineartype interproglottidal glands and not gland that are grouped as rosettes. These findings indicate that the genetic relation- ships among Moniezia spp. were not entirely relevant to the morphological similarity of their diagnostic interproglottidal glands. However, the phylogenetic relationship needs to be confirmed by using sequence data of other Moniezia species belonging to the 2 subgenera.

\section{REFERENCES}

1. Amer, S., Dar, Y., Ichikawa, M., Fukuda, Y., Tada, C., Itagaki, T. and Nakai, Y. 2011. Identification of Fasciola species isolated from Egypt based on sequence analysis of genomic (ITS1 and ITS2) and mitochondrial (NDI and COI) gene markers. Parasitol. Int. 60: 5-12. [Medline] [CrossRef]

2. Fukui, M. 1960. Studies on Moniezia expansa and its intermediate host. IV. A survey of Moniezia at a sheep run in the suburbs of Tokyo. J. Jpn. Vet. Med. Assoc. 13: 214-218 (in Japanese with English summary).

3. Itagaki, T., Kikawa, M., Sakaguchi, K., Shimo, J., Terasaki, K., Shibahara, T. and Fukuda, K. 2005. Genetic characterization of parthenogenic Fasciola sp. in Japan on the basis of the sequences of ribosomal and mitochondrial DNA. Parasitology 131: 679-685. [Medline] [CrossRef]

4. Katoh, K. and Standley, D. M. 2013. MAFFT multiple sequence alignment software version 7: improvements in performance and usability. Mol. Biol. Evol. 30: 772-780. [Medline] [CrossRef]

5. Machida, M., Matsumura, A. and Watanabe, S. 1974. A rare cestode, Moniezia monardi (Anoplocephalidas), from the Japanese serow. Bull. Nat. Sci. Mus. 17: 157-161.

6. Mori, Y. 1974. Moniezia benedeni infection in cattle. J. Vet. Clin. 127: 21-23 (in Japanese).

7. Quiazon, K. M. A., Yoshinaga, T., Santos, M. D. and Ogawa, K. 2009. Identification of larval Anisakis spp. (Nematoda: Anisakidae) in Alaska Pollock (Theragra chalcogramma) in Northern Japan using morphological and molecular markers. J. Parasitol. 95: 1227-1232. [Medline] [CrossRef]

8. Schmidt, G. D. 1986. Key to the genera Anoplocephalinae. pp. 421-451. In: Handbook of Tapeworm identification. CRC Press, Boca Raton.

9. Skrjabin, K. J. and Schulz, R. E. 1937. Helminthology, 2nd ed., Moskva.

10. Spassky, A. A. 1951. Essentials of cestodology, vol 1: Anoplocephalate tapeworms of domestic and wild animals. Academy of Sciences of the USSR, Moscow (English edition, 1961, Israel Program for Scientific Translations, Jerusalem).

11. Tamura, K., Peterson, D., Peterson, N., Stecher, G., Nei, M. and Kumar, S. 2011. MEGA5: Molecular evolutionary genetics analysis using maximum likelihood, evolutionary distance, and maximum parsimony methods. Mol. Biol. Evol. 28: 2731-2739. [Medline] [CrossRef]

12. Taylor, E. L. 1928. Moniezia: A genus of cestode worms, and the proposed reduction of its species to three. Proc. U.S. Natl. Mus. (Wash.) 74: 1-9.

13. Villalobos, N., González, L. M., Morales, J., de Aluja, A. S., Jiménez, M. I., Blanco, M. A., Harrison, L. J. S., Parkhouse, R. M. E. and Gárate, T. 2007. Molecular identification of Echinococcus granulosus genotypes (G1 and G7) isolated from pigs in Mexico. Vet. Parasitol. 147: 185-189. [Medline] [CrossRef] 